Bangladesh Journal of Anatomy January 2013, Vol. 11 No. 1 pp 7-10

\title{
Study of Number, Shape, Size and Position of Mental Foramen in Bangladeshi Dry Adult Human Mandible
}

\author{
Md. Mesbahul Hoque ${ }^{1}$, Shamim Ara ${ }^{2}$, Shahanaz Begum ${ }^{3}$, A.H.M. Mostafa Kamal ${ }^{4}$ \\ Md. Abdul Momen ${ }^{5}$
}

\begin{abstract}
Context: Paralysis of the mental nerve is one of the principal complications of surgery of the mandibular canal and mental foramen region. Therefore, identification of mental foramen is important for dental surgeons in nerve block and surgical procedures like apico curettage of mandibular premolars, amalgam filling, peridental surgery etc. to avoid injury to neurovascular bundle. Verification of the existence of accessory mental foramina would prevent accessory mental nerve injury during periapical surgery. Therefore, prior knowledge of morphology and morphometry of mental and accessory mental foramen to particular block may cause effective mental block anaesthesia. Besides this, mental foramen and accessory mental foramen have been found to vary in position in different ethnic groups. So, it is important to study the morphology and morphometry of mental foramen.
\end{abstract}

Materials and Methods: A cross-sectional, analytical type of study was conducted in the Department of Anatomy, Dhaka Medical College using dried adult human mandibles of unknown sexes. Number and shapes of mental foramen and accessory mental foramen were observed. Size and position were determined by using digital sliding calipers.

Result: Mental foramen was present in all one hundred and eighty five (185) observed mandibles and it was bilateral. Accessory mental foramen was present in $1.62 \%$ on left side while on right side, it was $0.54 \%$. None of the mandibles presented with bilateral accessory mental foramen. Shape was predominantly oval with $55.7 \%$ on right side and $53.5 \%$ on left side while it was round in $44.3 \%$ on right side and $46.5 \%$ on left side. Mental foramen was commonly located between $1^{\text {st }}$ and $2^{\text {nd }}$ premolar, below $2^{\text {nd }}$ premolar and between $2^{\text {nd }}$ premolar and $1^{\text {st }}$ molar.

Conclusion: Prior knowledge of mental foramen variations helps surgeon in planning surgery in that region to avoid nerve damage and also for effective mental nerve block anaesthesia.

Key words: Mental foramen, accessory mental foramen.

1. Assistant Professor, Department of Anatomy, Satkhira Medical College, Satkhira.

2. Professor and Head, Department of Anatomy, Dhaka Medical College, Dhaka.

3. Professor and Head, Department of Anatomy, National Institute of Cardiovascular Diseases, Dhaka

4. Assistant Professor, Department of Anatomy, Dhaka Medical College, Dhaka.

5. Assistant Professor, Department of Biochemistry, Ad-Din Women's Medical College, Dhaka.

Correspondence : Dr. Md. Mesbahul Hoque

\section{Introduction:}

Mental Foramen (MF) is an important anatomical landmark to facilitate surgical, local anesthetic and other invasive procedures for dental surgeons performing periapical surgery in the mental region of mandible. Prior knowledge of morphology and morphometry of mental foramen and accessory mental foramen (AMF) needs to be considered before any surgery in the foramina area in order to avoid any nerve damage. The MF is situated 
bilaterally on the anterolateral aspect of the mandible, down to alveolar margin. The mental nerve and vessels emerges through the mental foramen and supply sensory innervation and blood supply to the soft tissues of the chin, lower lip and gingiva ${ }^{1}$, 2. But the position of MF varies among racial groups and genders ${ }^{3,4}$. Any foramen in addition to MF is known as accessory mental foramen in the body of the mandible. A branch of mental nerve passes through the AMF. Hence size, shape, position and number of MF and AMF would facilitate the dental surgeon to apply nerve block in different surgical procedures involving lower jaw. In addition to this, if this nerve is not blocked, in the structures supplied by it, parasthesia will be less. Despite the significance of MF, little attention has been given to the study of the morphology, most common position of foramen and associated anatomical characteristics in Bangladesh; hence this study has been conducted to investigate the number, size, shape, and position of MF with respect to surgically encountered anatomical landmarks.

\section{Materials and Methods:}

One hundred and eighty five (185) dried adult human mandibles with complete dentition and intact alveolar margin of unknown sex obtained from the Department of Anatomy of Dhaka Medical College, Sir Salimullah Medical College and Shaheed Suhrawardy Medical College, Dhaka were used for this study. The number, shape and position of mental foramen were observed on the both sides of mandible. Mean horizontal and vertical diameters were measured by using digital sliding caliper. Position of MF was identified by using following parameters: (1) Distance from the mental foramen to alveolar margin and (2) Distance from mental foramen to inferior border of the mandible. The position of MF was noted in relation to mandibular teeth. A comparison of the mean values between sides was performed using the paired ' $t$ '-test and Chi-square test, $p$-value d"0.05 was considered statistically significant.

\section{Results:}

Morphometric features of 185 (one hundred and eighty five) dried human mandibles revealed that the single number of MF on right side present was in $99.46 \%$ cases and on left side in $98.38 \%$ cases, whereas double in $0.54 \%$ cases and $1.62 \%$ cases on right side and left side (Table-I). The shape of foramen was oval in $55.7 \%$ cases and round in $44.3 \%$ cases on right side and $53.5 \%$ cases oval and $46.5 \%$ cases round on left side (Table-II). The linear measurements of MF with respect to anatomical landmarks are given in table-III. The positions of mental foramen in relation to mandibular teeth on both two sides are shown in table-IV. The most frequent position of mental foramen in relation to the teeth was between $1^{\text {st }}$ and $2^{\text {nd }}$ premolar for right side in $42.2 \%$ and for left side in $42.7 \%$ cases. The second common position was below $2^{\text {nd }}$ premolar for right side in $35.6 \%$ and for left side in $36.2 \%$ cases. The third common position was between $2^{\text {nd }}$ premolar and $1^{\text {st }}$ molar for right side in $22.2 \%$ cases and for left side in $21.1 \%$ cases.

Table-I

Number of Mental foramen on right and left side of the mandible

\begin{tabular}{llll}
\hline Side & & No. of foramen \\
& Single (\%) & Double $(\%)$ & Total \\
\hline Right & $184(99.46 \%)$ & $01(0.54 \%)$ & 185 \\
Left & $182(98.38 \%)$ & $03(1.62 \%)$ & 185 \\
\hline
\end{tabular}

Table-II

Shape of the mental foramen at the right and left side of the mandible

\begin{tabular}{lccc}
\hline Sidel & \multicolumn{2}{c}{ Total $(\mathrm{N}=185)$} & $P$ \\
\cline { 2 - 3 } Shape & No & $(\%)$ & value \\
\hline Right side & & & \\
Oval & 103 & $(55.7)$ & $>0.50^{\text {ns }}$ \\
Round & 82 & $(44.3)$ & \\
Left side & & & \\
Oval & 99 & $(53.5)$ & $>0.50^{\text {ns }}$ \\
Round & 86 & $(46.5)$ & \\
\hline
\end{tabular}

Comparison of shape between right and left side done by Chi square test, ns = not significant 
Bangladesh J. Anat. 2013; 11(1) : 7-10

Table-III

Morphometric measurements of mental foramen

\begin{tabular}{|c|c|c|c|}
\hline Characteristics & $\begin{array}{c}\text { Right side } \\
(\text { mean } \pm S D) \mathrm{mm}\end{array}$ & $\begin{array}{c}\text { Left side } \\
(\text { mean } \pm S D) m m\end{array}$ & Pvalue \\
\hline Horizontal diameter of MF & $2.56 \pm 0.67$ & $2.49 \pm 0.50$ & $\tilde{\mathrm{A}} 0.05^{\mathrm{ns}}$ \\
\hline Vertical diameter of MF & $1.99 \pm 0.47$ & $1.93 \pm 0.39$ & Â0.05* \\
\hline Distance between MF and alveolar margin of mandible & $13.84 \pm 2.25$ & $13.61 \pm 2.24$ & $\hat{A} 0.05^{*}$ \\
\hline Distance between MF and lower border of mandible & $13.44 \pm 1.47$ & $13.57 \pm 1.66$ & $\tilde{A} 0.10^{\text {ns }}$ \\
\hline
\end{tabular}

Comparison between right and left side done by paired Student's 't' test, ns= not significant, *= significant.

Table-IV

Position of mental foramen in relation to teeth socket of the mandible

\begin{tabular}{lcc}
\hline Location & Right side & Left side \\
\hline Between $1^{\text {st }}$ and 2 ${ }^{\text {nd }}$ premolar & $42.2 \%$ & $42.7 \%$ \\
Below 2 ${ }^{\text {nd }}$ premolar & $35.6 \%$ & $36.2 \%$ \\
Between $1^{\text {st }}$ molar and 2 & $22.2 \%$ & $21.1 \%$ \\
premolar & & \\
\hline
\end{tabular}

Comparison among location within right and left side done by Chi- square test, but statistically not significant

\section{Discussion:}

In the present study, single mental foramen was most common. But double mental foramen was found in $0.54 \%$ on right side and in $1.62 \%$ on left side of the mandible. According to Oliveira et al. ${ }^{5}$ the single mental foramen was found in $97.5 \%$ and double mental foramen in $25 \%$ out of 80 total mandible.

In our study, on right side it was oval in $55.7 \%$ cases and round in $44.3 \%$ cases. On left side it was oval in $53.5 \%$ cases and round in $46.5 \%$ cases. This was similar to Mbajiorgu et al. ${ }^{6}$ due to same race but differed from Oliveira et al. ${ }^{5}$ where oval and round shaped mental foramen were found in $73.8 \%$ and $26.2 \%$ mandible respectively due to racial variation.

In the present study, the mean $( \pm S D)$ horizontal diameter of mental foramen on right side was slightly greater than that on left side of the mandible which was consistent with Oliveira et al. ${ }^{5}$ and Wang et al. ${ }^{7}$ but not consistent with Oguz and Bozkir ${ }^{8}$, where the horizontal diameter of mental foramen was 2.93 $\mathrm{mm}$ on the right side and $3.14 \mathrm{~mm}$ on the left side.

The mean $( \pm S D)$ vertical diameter of mental foramen was same on right and left side of the mandible which was similar with previous studies of Wang et al. ${ }^{7}$, Oguz and Bozkir ${ }^{8}$, Oliveira et al. ${ }^{5}$.

Position in relation to distance from alveolar ridge or inferior margin of mandible.

The mean $( \pm S D)$ distance between mental foramen and alveolar ridge was greater on right side than that on left side of the total mandibles. In other studies such as Wang et al. ${ }^{7}$, Oguz and Bozkir ${ }^{8}$, Oliveira et al, ${ }^{5}$ Agarwal and Gupta ${ }^{9}$ also showed that the distance was greater on right side than that on left side of the mandible.

The mean $( \pm S D)$ distance between mental foramen and inferior margin of the mandible was lower on right side than that on left side of the total mandibles. The result of this variable was similar to Wang et $\mathrm{al}^{7}$ and Oliveira et $\mathrm{al}^{5}$ but differed from Oguz and Bozkir ${ }^{8}$ Agarwal and Gupta $^{9}$, where this distance was slightly greater on right side $(14.61 \mathrm{~mm})$ than that on left side $(14.29 \mathrm{~mm})$ which might be due to technical error.

In the present study, the mental foramen was commonly located between $1^{\text {st }}$ and $2^{\text {nd }}$ premolar teeth sockets which was consistent with Oguz and Bozkir ${ }^{8}$ but differed from Simonton ${ }^{10}$, Wang et al. ${ }^{7}$, Oliveira et al. ${ }^{5}$ Agarwal and Gupta ${ }^{9}$, where the most common location was at the root of the $2^{\text {nd }}$ premolar teeth which might be due to racial variations and researchers' observational error. 


\section{Conclusion}

The present analysis revealed variations in number, shape, size and position of MF and AMF. The variability of the position of MF and AMF should alert the dental surgeons while performing periodontal or endodontic surgery. Morphology and morphometry of MF and AMF when studied on larger sample size can be used as anthropological tool by anthropologists to identity deceased.

\section{References}

1. Sinnathamby CS: Last's Anatomy: Regional and Applied. 10th Edn.; Churchill Livingstone, Edinburgh 1999: 506.

2. Beale TJ, Robinson PD. Infratemporal and Pterygopalatine fossae and Temporomandibular joint. In: Standring s, Boreley NR, Healy JC, Collins P, Johnson D, Crossman AR, et al. eds. Gray's Anatomy: The anatomic basis of clinical practice. $40^{\text {th }} \mathrm{ed}$. UK: Elsevier Churchill Livingstone 2008: 530-33.

3. Cutright B, Quillopa N, Schubert W. An anthropometric analysis of the key foramina for maxillofacial surgery. Oral Maxillofac. Surg. 2003; 61(3): 354-57.

4. Defreitas V, Madeira MC, Pinto CT, Zorzetto NL. Direction of the mental canal in human mandibles. Aust Dent. J 1979; 21(4): 338-40.
5. Oliveira JEM, Araujo ALD, Dasilva CMF, Sousa RCF, Lima FJC. Morphological and morphometric study of the mental foramen on the $\mathrm{M}$ CP-18 jiachenjiang point. Int. J. Morphol 2009; 27(1): 231-38.

6. Mbajiorgu FE, Zivanovic S, Asala SA, Mawera G. A pilot study of the mandibular angle in black Zimbabweans. Cent Afr J med 1996; 42(10): 285-87.

7. Wang TM, Shih C, Liu JC, Kuo KJA. A clinical and anatomical study of the location of the mental foramen in adult Chines mandibles. Acta Anat 1986; 126(1):29-33.

8. Oguz O, Bozkir MG. Evaluation of the location of the mandibular and mental foramina in dry, young, adult human male, dentulous mandibles. West Indian Med. J 2002; 51(1): 6-14.

9. Agarwal DR, Gupta SB. Morphometric analysis of mental foramen in human mandibles of south Gujrat. People's Journal of Scientific Research 2011; 4(1): 15-18.

10. Simonton FV. Mental foramen in the Anthropoids and in man. Am. J. Physiol. Anthrop 1923; 6: 413-21. 